\title{
Arquivistas e Museólogos: uma reflexão crítica sobre o posicionamento destes profissionais na Classificação Brasileira de Ocupações
}

\author{
Archivists and Museologists: a critical reflection on the positioning of these professionals in \\ the Brazilian`s Classification of Occupations
}

Helena Maria Tarchi Crivellari

Doutora em Educação pela Universidade Estadual de Campinas - UNICAMP. Docente no Programa de Pós-Graduação em Ciência da Informação da Universidade Federal de Minas Gerais E-mail: helenacrivellari@gmail.com

Thiara dos Santos Alves
Mestre em Ciência da Informação pela Universidade Federal de Minas Gerais. E-mail: thialves@yahoo.com.br

Maria Guiomar da Cunha Frota

Doutora em Sociologia pelo Instituto Universitário de Pesquisas do Rio de Janeiro. Docente no Programa de Pós-Graduação em Ciência da Informação, da Universidade Federal de Minas Gerais. E-mail: frotaguiomar@yahoo.com.br

\begin{abstract}
Resumo
Este artigo apresenta alguns resultados de estudo já concluído e tem por objetivo contribuir para uma reflexão crítica sobre o posicionamento dos profissionais Arquivistas e Museólogos, na Classificação Brasileira de Ocupações. A pesquisa foi feita através de levantamento bibliográfico e documental. A relevância deste artigo consiste em procurar suprir, ao menos parcialmente, a escassez de pesquisas sobre a Família Ocupacional "Arquivistas e Museólogos", bem como sobre o mercado de trabalho deste grupo; além de contribuir com apontamentos para uma possível atualização e revisão de parte do documento da Classificação Brasileira de Ocupações. O artigo contextualiza a formação e organização profissional do Arquivista e do Museólogo no Brasil; apresenta o histórico da Classificação Brasileira de Ocupações; em seguida, situa o Arquivista e o Museólogo na Classificação Brasileira de Ocupações; depois, exemplifica o uso da Classificação Brasileira de Ocupações na Relação Anual de Informações Sociais. Por fim, encerra-se com uma conclusão parcial que pretende colaborar para reflexões sobre: a construção das classificações de ocupação; a dificuldade de viabilizar propostas de políticas públicas de formação e emprego para Arquivistas e Museólogos; possíveis aspectos a respeito do emprego destes profissionais; as políticas microinstitucionais de descrição de cargos nos editais de concurso público.
\end{abstract}

Palavras-chave: Arquivista. Museólogo. Classificação Brasileira de Ocupações. Relação Anual de Informações Sociais.

\begin{abstract}
This article presents some results of completed research and aims to contribute to a critical reflection on the positioning of Archivists and Museologists professionals in the Brazilian`s Classification of Occupations. The research was conducted through bibliographical and documentary. The relevance of this article is to attempt to meet, at least partially, the lack of researches about Occupational Family "Archivists and Museologists", as well about the job market for these group; besides contributing to notes for a possible update and review of the Brazilian`s Classification of Occupations. The article analyzes the formation and organization of professional Archivist and Museologist in Brazil; it shows the history of the Brazilian`s Classification of Occupations; then, places the Archivist and the Museologist in the Brazilian`s Classification of Occupations; then, exemplifies the use of Brazilian`s Classification of Occupations in the Annual Report of Social Information. Finally, it ends with a partial conclusion that it want to contribute to reflections on: the construction of occupation classifications; the difficulty of viable public policy proposals for training and employment of Archivists and Museologists; possible aspects about the employment of these professionals; microinstitutional policies of job descriptions in the notices of public tender.
\end{abstract}

Keywords: Archivist. Museologist. Brazilian`s Classification of Occupations; Annual Report of Social Information.

InCID: R. Ci. Inf. e Doc., Ribeirão Preto, v. 8, n. 1, p. 46-67, mar./ago. 2017.

DOI: 10.11606/issn.2178-2075.v8i1p46-67 


\section{Introdução}

No Brasil, as profissões de Arquivista e Museólogo são regulamentadas, respectivamente, pela Lei ${ }^{\circ}$. 6.546/78, e pela Lei nº. 7.287/84 (BRASIL, 1978; BRASIL 1984). De acordo com a legislação, Arquivista é o diplomado em curso superior de Arquivologia1, já o título de Museólogo é atribuído tanto ao graduado em curso superior de Museologia quanto ao pós-graduado, em nível de Mestrado e Doutorado, em Museologia2.

Estes profissionais, Arquivistas e Museólogos, estão reunidos em uma mesma Família Ocupacional na Classificação Brasileira de Ocupações (CBO), em sua versão 2002, e alterações incluídas em 2013. A CBO é o "documento normalizador do reconhecimento (no sentido classificatório), da nomeação e da codificação dos títulos e conteúdos das ocupações do mercado de trabalho brasileiro" (BRASIL, 2010a).

O objetivo deste artigo é contribuir para uma reflexão crítica sobre o posicionamento dos profissionais Arquivistas e Museólogos na CBO. Para alcançar este objetivo, a pesquisa foi feita através de levantamento bibliográfico e documental, partindo do seguinte questionamento: qual é o posicionamento dos profissionais Arquivistas e Museólogos na Classificação Brasileira de Ocupações?

A relevância do tema abordado reside no fato de serem escassas as pesquisas sobre a Família Ocupacional "Arquivistas e Museólogos" e sobre o mercado de trabalho desses profissionais. Além disso, as reflexões sobre o posicionamento dos Arquivistas e Museólogos na CBO podem contribuir com apontamentos para uma possível atualização e revisão de parte de tal documento. Inclusive, a atualização da CBO já foi o objetivo de edital de chamada pública (BRASIL, 2010b) do Ministério do Trabalho e Emprego (MTE) e a revisão da descrição da profissão do Arquivista na CBO foi uma das recomendações da I Reunião Brasileira de Ensino e Pesquisa em Arquivologia (UNIVERSIDADE DE BRASÍLIA, 2010).

O presente artigo contextualiza a formação e a organização profissional do Arquivista e do Museólogo no Brasil. Nas seções seguintes, apresenta o histórico da Classificação Brasileira de Ocupações; em seguida, situa o Arquivista e o Museólogo neste sistema de classificação;

\footnotetext{
1 A legislação permitiu que se tornasse Arquivista também o profissional que, na data de início da vigência da Lei $\mathrm{n}^{\circ}$. 6.546/78, contava com experiência no campo profissional da Arquivologia de, no mínimo, cinco anos ininterruptos de atividade ou dez intercalados.

2 A legislação também permitiu que se tornasse Museólogo o profissional com outro curso de nível superior que, no prazo de três anos contados a partir da vigência da Lei $\mathrm{n}^{\circ}$. 7.287/84, comprovou experiência em atividades técnicas de Museologia e tal experiência foi validada pelos Conselhos Regionais de Museologia.
} 
depois, exemplifica o uso da CBO na Relação Anual de Informações Sociais (RAIS/MTE), a partir dos dados disponíveis nas bases estatísticas da RAIS/MTE referentes ao ano de 2014. Por fim, o artigo apresenta uma conclusão parcial a partir da literatura e dos primeiros dados levantados.

\section{Formação e organização profissional do Arquivista e do Museólogo no Brasil}

Correspondendo às exigências legais, os cursos de graduação em Arquivologia e Museologia são o principal meio de formação desses profissionais. Antes de serem criados os cursos universitários de Arquivologia, os profissionais que atuavam no Arquivo Nacional e nos demais arquivos brasileiros eram capacitados, principalmente, pelas instituições arquivísticas (MARQUES, 2012).

O primeiro curso regular de Arquivologia no Brasil foi o Curso Permanente de Arquivo (CPA), com duração de dois anos, o qual teve início em 1960, no Arquivo Nacional. No final da década de 1970, esse curso foi transferido para a Federação das Escolas Federais Isoladas do Estado do Rio de Janeiro (atual Universidade Federal do Estado do Rio de Janeiro UNIRIO), conquistando o espaço universitário, passando a ser designado como curso de Arquivologia (MARQUES; RODRIGUES, 2011).

Segundo Rodrigues (2011), seguindo tendências internacionais, após os anos de 1990, no Brasil, a centralidade do ensino e de pesquisa deslocou-se das instituições arquivísticas públicas para as universidades. Existem, hoje, dezesseis cursos de Arquivologia no Brasil, os quais são presenciais, formam bacharéis e são ofertados por universidades públicas.

Souza (2011) fez um mapeamento do período em que as universidades criaram os cursos de Arquivologia. Segundo a autora, os primeiros cursos de Arquivologia no Brasil foram criados na década de 1970: Universidade do Rio de Janeiro (UNIRIO), Universidade Federal de Santa Maria (UFSM) e Universidade Federal Fluminense (UFF). Na década de 1990, foram criados cinco cursos universitários de Arquivologia: Universidade de Brasília (UnB), Universidade Estadual de Londrina (UEL), Universidade Federal da Bahia (UFBA), Universidade Federal do Rio Grande do Sul (UFRGS) e Universidade Federal do Espírito Santo (UFES). A partir dos anos 2000, foram criados outros oito cursos: Universidade Estadual Paulista "Júlio de Mesquita Filho" (UNESP), em 2003; Universidade Estadual da Paraíba (UEPB), em 2006; Universidade Federal do Rio Grande (FURG) e Universidade Federal da 
Paraíba (UFPB), em 2008; Universidade Federal do Amazonas (UFAM) e Universidade Federal de Minas Gerais (UFMG), em 2009; Universidade Federal de Santa Catarina (UFSC), em 2010, e Universidade Federal do Pará (UFPA), em 2012.

Para além da Graduação, a partir da década de 1990, houve um aumento de dissertações e teses com temáticas arquivísticas, principalmente, na área de Ciência da Informação (SANTOS, 2012). Recentemente, em 2012, a UNIRIO lançou o Mestrado Profissional em Gestão de Documentos e Arquivos (PPGARQ), que inaugurou uma nova experiência na qualificação dos Arquivistas. Os profissionais também puderam dar continuidade aos estudos por meio dos cursos de especialização.

Atualmente, os Arquivistas estão organizados profissionalmente em associações estaduais - em São Paulo, no Rio de Janeiro, na Bahia, em Brasília, no Rio Grande do Sul, no Espírito Santo, no Paraná, em Goiás, em Minas Gerais, na Paraíba, no Ceará e em Santa Catarina - e na Associação Brasileira de Profissionais da Informação (ABRAINFO). Todas as associações estaduais estão congregadas, desde 2014, no Fórum Nacional das Associações de Arquivistas do Brasil (FNArq), o qual é um colegiado que reúne, coordena e representa os interesses das associações.

Cabe destacar que a fiscalização do exercício profissional, no Brasil, é responsabilidade dos Conselhos de Fiscalização de Atividades Profissionais. Todavia, ainda não existe um Conselho Profissional para os Arquivistas brasileiros e o exercício da profissão depende de registro na Delegacia Regional do Trabalho (BRASIL, 1978, art. $4^{\circ}$ ). É importante esclarecer que o Conselho Nacional de Arquivos é um órgão vinculado ao Arquivo Nacional, o qual define a política nacional de arquivos (BRASIL, 1991, art.26); não correspondendo, portanto, a uma instituição de representação profissional.

Quanto à formação de Museólogos, o Museu Histórico Nacional (MHN), em 1932, criou o Curso de Museus, com duração de dois anos. Esta iniciativa pioneira tinha o intuito de habilitar, em nível técnico, profissionais para a atuação em museus nacionais de História, Belas Artes e Arte Religiosa. O regulamento do Curso foi aprovado em 1944 pelo Decreto $\mathrm{n}^{\circ}$. 66.689/44, que também ampliou a duração do curso para três anos. Em 1951, a Universidade do Brasil (atual Universidade Federal do Rio de Janeiro - UFRJ) conferiu ao curso mandato universitário e ampliou sua matriz curricular (SÁ, 2013). 
Em 1963, foi fundada a Associação Brasileira de Museologia e, em 1969, criou-se o segundo curso de Museologia do Brasil, na Universidade Federal da Bahia (UFBA), que passou a funcionar no ano seguinte. Na década de 1970, o MHN criou, no Curso de Museus, a habilitação em Museus de Ciências e, em 1977, o curso foi integrado à Federação das Escolas Federais Isoladas do Estado do Rio de Janeiro (FEFIERJ) - atual UNIRIO. No ano de 1979, o Curso de Museus desvinculou-se do MHN e passou a funcionar na UNIRIO. Também nesta década, o curso de Museologia da Faculdade de Arqueologia e Museologia Marechal Rondon (FAMARO), transferido anos depois para as Faculdades Integradas Estácio de Sá (FINES), graduou Museólogos no Brasil, todavia, o curso encerrou-se em 1995 (TANUS, 2013).

A Lei $n^{\circ}$. 7.287/84, que dispõe sobre a regulamentação da profissão do Museólogo, criou o Conselho Federal de Museologia (COFEM) e os Conselhos Regionais de Museologia (COREM), que são órgãos que, entre outras atribuições, registram os profissionais e fiscalizam o exercício da profissão. Nunes, Oliveira e Costa (2010, p. 3) consideram que "este marco regulatório reforçou e consolidou a importância imprescindível dos cursos de graduação em Museologia como meio para a formação de profissionais para o setor”.

Além dos cursos ofertados pela UNIRIO e pela UFBA, recentemente, foram criados vários cursos de graduação em Museologia: em 2004, no Centro Universitário de Barriga Verde (UNIBAVE), em Santa Catarina; em 2006, na Universidade Federal de Pelotas (UFPEL) e na Universidade Federal do Recôncavo Baiano (UFRB); em 2007, na Universidade Federal de Sergipe (UFS); em 2008, na Universidade Federal de Ouro Preto (UFOP) e na Universidade Federal do Rio Grande do Sul (UFRGS); em 2009, na Universidade de Brasília (UnB), na Universidade Federal de Pernambuco (UFPE) e na Universidade Federal do Pará (UFPA); em 2010, na Universidade Federal de Goiás (UFG), na Universidade Federal de Minas Gerais (UFMG) e na Universidade Federal de Santa Catarina (UFSC). Também está cadastrado junto ao Ministério da Educação, o curso de Museologia da Faculdade Dom Bosco de Monte Aprazível (FAECA/SP), contudo, ainda não houve a formação de turmas para iniciar as atividades.

Para formar Museólogos no Brasil, além dos cursos de Graduação, existem, atualmente, quatro programas de Pós-Graduação strictu sensu. O Programa de Pós-Graduação em Museologia e Patrimônio (PPG-PMUS), parceria entre a UNIRIO e o Museu de Astronomia e Ciências Afins (MAST), oferta, desde 2006, o Mestrado em Museologia e Patrimônio e, desde 2011, o Doutorado em Museologia e Patrimônio. A Universidade de São Paulo forma mestres 
em Museologia desde 2012, através do Programa de Pós-Graduação Interunidades em Museologia. A Universidade Federal da Bahia criou, em 2012, o Programa de Pós-Graduação de Museologia, que forma mestres para a área. A mais nova oferta de Pós-Graduação em Museologia foi iniciativa da Universidade Federal do Piauí, que, em 2015, iniciou o Mestrado Profissional em Artes, Patrimônio e Museologia. A temática museológica está contemplada em outros programas de Pós-Graduação que não formam Museólogos, como, por exemplo, os diversos programas de Pós-Graduação na área de Ciência da Informação, História e Memória Social.

Os cursos de graduação de Arquivologia e Museologia mais recentes foram impulsionados, a partir de 2008, pelo Programa de Apoio a Planos de Reestruturação e Expansão das Universidades Federais (REUNI). Desta forma, o REUNI foi responsável pela criação de seis cursos de Arquivologia e oito de Museologia.

\section{A Classificação Brasileira de Ocupações}

A CBO teve sua estrutura básica elaborada em 1977, sendo produto do convênio realizado entre o Brasil e a Organização das Nações Unidas (ONU), através da intermediação da Organização Internacional do Trabalho (OIT). Os estudos iniciais para a elaboração da CBO tiveram como referência a Classificação Internacional Uniforme de Ocupações (CIUO), de 1968 (BRASIL, 2010a).

A elaboração, gestão, manutenção e atualização da CBO é atribuição do MTE. A CBO é um instrumento classificatório que ordena e descreve as ocupações dentro de uma estrutura hierarquizada, a qual possibilita reunir as informações sobre a força de trabalho, de acordo com características ocupacionais referentes à natureza da força de trabalho - funções, tarefas e obrigações da ocupação - e ao conteúdo do trabalho - conhecimentos, habilidades, atributos pessoais e demais requisitos exigidos para exercer a ocupação (INSTITUTO BRASILEIRO DE GEOGRAFIA E ESTATÍSTICA, 2015).

A padronização proposta pela CBO é de ordem administrativa e não abrange as relações de trabalho (BRASIL, 2002a). Deste modo, é importante salientar que a regulamentação das profissões é realizada por meio de lei, apreciada pelo Congresso Nacional e sancionada pelo Presidente da República Federativa do Brasil, e que a CBO classifica as diversas atividades profissionais, sem fazer a distinção entre profissões de livre exercício e as profissões 
regulamentadas. Além disso, cabe destacar que a CBO pode auxiliar na formulação de políticas de educação e trabalho, todavia, não é um documento normalizador, mas orientador para a elaboração de currículos dos cursos que formam os profissionais e para a organização de carreiras.

Após sua elaboração, em 1977, a CBO passou por atualizações pontuais, que não alteravam sua metodologia nem sua estrutura, como, por exemplo, em 1982, quando foi lançada a CBO 82. No ano de 1988, foi publicada uma nova versão da Classificação Internacional Uniforme de Ocupações (CIUO-88), editada em espanhol, que alterava os critérios de agregação dos grupos ocupacionais (BRASIL, 2010a). A adoção da CIUO-88 pela CBO, com algumas adaptações, demandou um longo processo de estudos e trabalhos que se concretizaram apenas em 2002. Antes disso, em 1994, entrou em vigor a Portaria $n^{\circ} .1 .334 / 94$, que aprovou a Classificação Brasileira de Ocupações - CBO, versão 94, para uso em todo o país.

Antes de ser publicada a atual versão de 2002 da CBO, as informações administrativas relativas às ocupações utilizavam os códigos da CBO versão de 1994, entretanto, os dados censitários e as pesquisas domiciliares realizadas pelo Instituto Brasileiro de Geografia e Estatística (IBGE) usavam uma nomenclatura própria, sem descrições. A multiplicidade de classificações ocupacionais "dificultava a comparabilidade entre os usuários de diferentes fontes de informações produzidas no território nacional, com o agravante de dificultar a comparação dessas estatísticas com aquelas geradas em outros países” (BRASIL, 2010a). Ocorreu, então, um esforço de articulação entre os órgãos brasileiros na tentativa de unificar as diferentes classificações de ocupação. Assim, em 1994, com esta finalidade, foi instituída a Comissão Nacional de Classificações (CONCLA) (BRASIL, 2010a).

A partir deste momento, o MTE e o IBGE somaram esforços na elaboração da classificação. A construção da nova classificação foi organizada pela Divisão de Classificação Brasileira de Ocupações (DCBO), que, para facilitar o desenvolvimento do projeto, o dividiu em três módulos (BRASIL, 2010a).

O primeiro módulo resultou na tábua de conversão, publicada em 1996, a qual viabilizou a comparação das estatísticas, que adotavam a classificação do IBGE, de 1991, e os registros administrativos, que utilizavam a CBO 1994, através da compatibilização dos títulos ocupacionais. Todavia, os critérios para agregar os grupos ocupacionais e as definições não foram modificados (BRASIL, 2010a). O segundo módulo consistiu na "elaboração e validação 
da estrutura [da tábua de conversão], já com a alteração de conceitos de agregação, utilizandose o modelo CIUO 88, com algumas adaptações” (BRASIL, 2010a).

O último módulo consistiu na "escolha de um modelo de descrição e a organização de uma rede de parceiros para a construção da classificação descritiva” (BRASIL, 2010a). A descrição das Famílias Ocupacionais utilizou, com adaptações, o método Dacum - Developing A Curriculum - difundido nos Estados Unidos e no Canadá há mais de 40 anos. Ele parte do seguinte princípio: "quem melhor descreve o trabalho é quem o desempenha" (BRASIL, 2010b). O processo descritivo foi delegado aos ocupantes da profissão, orientados por um facilitador/relator qualificado na aplicação do método Dacum. Para conduzir o trabalho, reuniram-se de oito a doze trabalhadores, organizados em oficinas de trabalho (painel), com duração de dois dias, para a descrição da ocupação, e de um dia para revisão, por outro comitê formado por trabalhadores. O uso do método Dacum, no Brasil, permitiu a descrição de 596 Famílias Ocupacionais, em três níveis3: Titulação; Grande Área de Competência (GAC); e Atividades. (BRASIL, 2010b).

Em 1999, foi feita a descrição-piloto das Famílias Ocupacionais, a partir do método Dacum, pelo Serviço Nacional de Aprendizagem Industrial (SENAI) do Rio de Janeiro. Nos anos seguintes, foram treinados facilitadores da Fundação Instituto de Pesquisas Econômicas (Fipe) - Universidade de São Paulo -; da Fundação de Desenvolvimento da Unicamp (Funcamp) - Universidade Estadual de Campinas (UNICAMP) -; e da Fundação de Desenvolvimento da Pesquisa - da Universidade Federal de Minas Gerais. Além disso, houve a participação de serviços de uma consultoria nacional, o treinamento dos facilitadores do método Dacum (feito por uma instituição canadense) e a participação de uma perita da OIT. Os trabalhos encerraram-se em agosto de 2002 (BRASIL, 2010a).

A elaboração da versão 2002 da CBO resultou na realização de 1.800 reuniões-dia, na participação de aproximadamente 7 mil trabalhadores (BRASIL, 2010a), 3.000 empresas, 1.000 sindicatos e outras entidades de classe (BRASIL, 2010b). Isto representa uma relevante participação do mercado de trabalho do Brasil, portanto, "torna-se legítimo considerar que a CBO 2002 representa um dos mais abrangentes processos de coleta de dados sobre o mercado

\footnotetext{
3 São cinco os níveis do método Dacum para inventariar as atividades ocupacionais: $1^{\circ}$ - Titulação; $2^{\circ}$ - GAC (Grande Área de Competência); $3^{\circ}$ - Atividades; $4^{\circ}$ - Sub atividades; $5^{\circ}$ - Indicador de Desempenho (BRASIL, 2010b).
} 
de trabalho no Brasil, tendo por referência a última classificação proposta pela OIT - a CIOU88” (BRASIL, 2010b).

A Portaria $\mathrm{n}^{\mathrm{o}} .397$, de 09 de outubro de 2002, aprovou a CBO, versão 2002, para uso em todo o território nacional e determinou que os títulos e códigos da CBO sejam usados: nas atividades de registro, inscrição, colocação e outras desenvolvidas pelo Sistema Nacional de Emprego (SINE); na Relação Anual de Informações Sociais (RAIS); nas relações dos empregados admitidos e desligados (Cadastro Geral de Empregados e Desempregados CAGED), de que trata a Lei nº. 4923/65; na autorização de trabalho para mão de obra estrangeira; no preenchimento do Comunicado de Dispensa para requerimento do benefício Seguro Desemprego; no preenchimento da Carteira de Trabalho e Previdência Social (CTPS) no campo relativo ao contrato de trabalho; nas atividades e programas do MTE, quando for o caso.

O código ocupacional da CBO é também utilizado por outros órgãos e instituições, por exemplo: a Secretaria da Receita Federal o utiliza na Declaração do Imposto de Renda; o Ministério da Saúde o adota na Rede Interagencial de Informações para a Saúde (RIPSA); o Ministério da Previdência Social o aplica nos registros de aposentadoria e benefícios; o IBGE o utiliza nas Pesquisas Domiciliares; o Mercado Comum do Sul (MERCOSUL), na comparabilidade ocupacional em nível de três dígitos; a CONCLA o usa nas tabelas de conversão entre as várias classificações; o SENAI e o Serviço Nacional de Aprendizagem Comercial (SENAC) o utilizam nas pesquisas e planejamento das agências de educação profissional; as Empresas e Entidades, na elaboração de Planos de Cargos e Salários; e o Ministério da Educação (MEC) o adota no Censo Educacional (BRASIL, 2010b).

A versão 2002 da CBO, baseada na CIUO-88, é mais enxuta se comparada à versão anterior, CBO-1994, e possui aproximadamente 10 Grandes Grupos, 47 Subgrupos principais, 192 Subgrupos e 596 Grupos de base ou Famílias Ocupacionais (INSTITUTO BRASILEIRO DE GEOGRAFIA E ESTATÍSTICA, 2015), e 2.422 ocupações (e seus 7.258 sinônimos para os títulos ocupacionais) (JANNUZZI; LOUREIRO, 2003).

Os conceitos de Ocupação e de Família Ocupacional são centrais na definição da CBO 2002. A Família Ocupacional - representada pelo código de 4 números - é a "unidade de classificação descritiva mais desagregada" (BRASIL, 2010a). A Família Ocupacional ou Grupo de Base é uma categoria sintética atrelada ao conceito de Ocupação, que "correspondente a um 
conjunto de ocupações similares que integram um domínio de trabalho mais amplo do que aquele da ocupação" (NOZOE; BIANCHI; RONDET, 2003, p.235).

A Ocupação, por sua vez, - representada por 5 dígitos - é um conceito artificialmente construído pelos analistas ocupacionais, que representa "a agregação de empregos ou situações de trabalho similares quanto às atividades realizadas" (BRASIL, 2010a); refere-se também ao conjunto de empregos e/ou postos de trabalho, substancialmente similares quanto à natureza $\mathrm{e}$ às qualificações exigidas, constituindo-se de funções, tarefas, obrigações e responsabilidades atribuídas a cada trabalhador, para a obtenção de produtos e serviços (BRASIL, 2010a).

As Ocupações são categorias dinâmicas e complexas que recebem e produzem influências no contexto social e econômico. Deste modo, novas ocupações podem surgir, bem como, certas ocupações podem desaparecer. A estrutura ocupacional, no Brasil, modificou-se de acordo com as transformações do mercado de trabalho: "de uma maneira geral, estão sendo presenciadas mudanças cuja natureza não é auto-evidente, mas cuja direção é importante entender para a definição de políticas públicas adequadas" (NOZOE, BIANCHI; RONDET, 2003, p.238).

A atualização sistemática da CBO é uma novidade da versão 2002. Nos anos seguintes à nova versão da $\mathrm{CBO}$, se deu sequência aos trabalhos de atualização e de manutenção de uma rede de informações ocupacionais, organizada em banco de dados, apoiada pelas instituições conveniadas que atualiza a base continuamente e incrementa novos desenvolvimentos, sob a coordenação do MTE (BRASIL, 2010a). 


\section{Arquivistas e Museólogos na CBO}

A CBO, na versão de 1994, reunia os Arquivistas, Bibliotecários e Museólogos no Grande Grupo de número 1, intitulado "Trabalhadores das Profissões Científicas, Técnicas, Artísticas e Trabalhadores Assemelhados". No interior deste grupo, os Arquivistas, Bibliotecários e Museólogos estavam no Subgrupo 1-9, “Trabalhadores das Profissões Científicas, Técnicas, Artísticas e Trabalhadores Assemelhados Não-Classificados sob Outras Epígrafes".

O Subgrupo 1-9 foi subdividido em Grupos de base, entre os quais se encontra o de número 1-91, denominado "Bibliotecários, arquivologistas e museólogos". Este Grupo era composto pelas seguintes ocupações: "Bibliotecário" (código 1-91.20), "Documentalista" (código 1-91.25), “Arquivologista" (código 1-91.30), "Museólogo" (código 1-91.40), Administrador de banco de dados (código 1-91.45) e "Outros bibliotecários, arquivologistas e museólogos" (código 1-91.90). O Quadro 1, a seguir, apresenta os códigos, títulos, sinônimos e a descrição resumida das ocupações que dizem respeito às profissões objeto deste artigo, Arquivistas e Museólogos.

A nova versão da CBO, de 2002, apresentou várias mudanças se comparada à versão anterior. Estas mudanças também impactaram as ocupações que compunham o Grupo de base "Bibliotecários, arquivologistas e museólogos", presente na versão de 1994. O título ocupacional "Outros bibliotecários, arquivologistas e museólogos", da versão de 1994, por exemplo, deixou de existir na CBO 2002.

Outra diferença a ser observada entre as versões da CBO de 1994 e de 2002 é o título do profissional de arquivos. Na versão de 1994, este profissional era identificado como “Arquivologista”. Já na versão de 2002, passou a ser conhecido como Arquivista, que é a denominação utilizada na Lei $\mathrm{n}^{\circ}$. 6.546/78, que regulamentou a profissão. 


\begin{tabular}{|c|c|}
\hline Código - Título (Sinônimos) & Descrição Resumida - CBO 1994 \\
\hline $\begin{array}{l}\text { 1-91.30 - Arquivologista (Chefe de seção de } \\
\text { serviço de arquivo médico e estatística. Chefe de } \\
\text { serviço de comunicação e arquivo. Encarregado de } \\
\text { arquivo de computadores. Encarregado de arquivo } \\
\text { de desenhos. Encarregado de arquivo de desenhos e } \\
\text { cópias. Encarregado de arquivo e faturamento. } \\
\text { Encarregado de arquivo fiscal. Encarregado de } \\
\text { arquivo geral. Encarregado de arquivo médico). }\end{array}$ & $\begin{array}{l}\text { Estuda e organiza documentos históricos, } \\
\text { científicos, literários e de outra natureza, } \\
\text { analisando-os e selecionando-os por assunto e } \\
\text { dando-lhes tratamento técnico sistematizado, para } \\
\text { armazená-los em arquivos adequados, recuperar } \\
\text { informações, facilitar sua consulta e evitar que os } \\
\text { mesmos se deteriorem. }\end{array}$ \\
\hline $\begin{array}{l}\text { 1-91.40 - Museólogo (Assistente de museu e } \\
\text { gabinete. Conservador de museu) }\end{array}$ & $\begin{array}{l}\text { Organiza, amplia e conserva, em um museu, } \\
\text { coleções de objetos de caráter artístico e outras } \\
\text { peças de igual valor e interesse, adotando sistemas } \\
\text { específicos de catalogação, classificação, } \\
\text { manutenção e divulgação, para facilitar a exposição } \\
\text { do acervo, possibilitar o controle das peças, auxiliar } \\
\text { pesquisadores em suas consultas e despertar maior } \\
\text { interesse no público. }\end{array}$ \\
\hline $\begin{array}{l}\text { 1-91.90 - Outros bibliotecários, arquivologistas e } \\
\text { museólogos (Filmotecário. Gerente de divisão de } \\
\text { obras de arte. Restaurador de livros e documentos. } \\
\text { Ajudante de documentação técnica. Auxiliar de } \\
\text { documentalista. Auxiliar de museus. Bibliotecário } \\
\text { tradutor. Subchefe de setor de cinemateca. } \\
\text { Supervisor de controle de volumes). }\end{array}$ & $\begin{array}{l}\text { Incluem-se aqui os bibliotecários, arquivologistas e } \\
\text { museólogos, não classificados nas anteriores } \\
\text { epígrafes deste grupo de base, por exemplo, os que } \\
\text { se especializam na aquisição, avaliação, } \\
\text { classificação, compilação e catalogação de } \\
\text { documentos sobre assuntos de interesse para } \\
\text { organizações comerciais e de outro gênero. }\end{array}$ \\
\hline
\end{tabular}

Quadro 1 - Código, Título, Sinônimo e Descrição resumida da CBO 1994 para as ocupações de "Arquivologistas", "Museólogo" e "Outros bibliotecários, arquivologistas e museólogos" Fonte: Dados obtidos na base CBO 1994 (BRASIL, [199-?]).

As Ocupações do Grupo de base "Bibliotecários, arquivologistas e museólogos", da versão de 1994, foram reorganizadas, na nova versão da CBO, dentro do Grande Grupo 2: "Profissionais das Ciências e das Artes". A instituição conveniada, responsável pela pesquisa das Ocupações pertencentes ao Grande Grupo 2, foi a Funcamp e os trabalhos foram coordenados pela professora Liliana Rolfsen Petrilli Segnini.

Dentro do Grande Grupo 2, as profissões de Arquivista, Bibliotecário, Documentalista e Museólogo estão classificadas no Subgrupo principal 26, "Comunicadores, Artistas e Religiosos", e também estão no mesmo Subgrupo, de número 261, "Profissionais da Comunicação e da Informação". Apenas o título ocupacional de Administrador de banco de dados, o qual também compunha o Grupo de base "Bibliotecários, arquivologistas e museólogos", na CBO 1994, não pertence ao Subgrupo principal 26, na versão da CBO 2002. Na nova versão da $\mathrm{CBO}$, os Administradores de banco de dados pertencem ao Subgrupo principal 21, "Profissionais das Ciências Exatas, Física e da Engenharia", e estão classificados no Subgrupo de número 212, denominado "Profissionais da Informática", estando inseridos na Família Ocupacional 2123, "Administradores de tecnologia da informação". 
O Subgrupo 261, "Profissionais da Comunicação e da Informação" é composto por oito4 Famílias Ocupacionais. Dentre estas, destaca-se a Família "Profissionais da Informação" (código 2612), que é composta pelas ocupações de Documentalista (código 2612-10), Analista de informações (pesquisador de informações de rede) (código 2612-15) e Bibliotecário (código 2612-05).

Arquivistas e Museólogos compõem, na CBO 2002, a Família Ocupacional de número 2613, intitulada “Arquivistas e Museólogos”, a qual agrega apenas estas duas ocupações5. A reunião somente das profissões de Arquivistas e Museólogos, na nova versão da CBO, aponta para a adoção adaptada da CIOU 88. Na estrutura da CIOU 88 o Grande Grupo 2: Profesionales científicos e intelectuales é composto pelo Subgrupo principal 26: Profesionales en derecho, en ciencias sociales y culturales (código 26); o Subgrupo principal 26 é formado pelo Subgrupo 262: Archivistas, bibliotecarios, curadores y afines; e, por fim, o Subgrupo 262 abriga os Grupos Primários 2621: Archivistas y curadores de museos e 2622: Bibliotecarios, documentalistas y afines (ORGANIZAÇÃO INTERNACIONAL DO TRABALHO, [200-?]).

$\mathrm{Na}$ CBO 2002, ambos os profissionais da Família Ocupacional “Arquivistas e Museólogos" são descritos da seguinte forma:

\begin{abstract}
Organizam documentação de arquivos institucionais e pessoais, criam projetos de museus e exposições, organizam acervos museológicos públicos e privados. Dão acesso à informação, conservam acervos. Preparam ações educativas ou culturais, planejam e realizam atividades técnico-administrativas, orientam implantação das atividades técnicas. Participam da política de criação e implantação de museus e instituições arquivísticas (BRASIL, 2002b).
\end{abstract}

A descrição apresentada tem sido utilizada em alguns editais6 de concursos públicos para apontar a descrição ou atribuição do cargo, por exemplo, apenas do Arquivista, e isto pode gerar equívocos sobre o campo de jurisdição legal do Arquivista e do Museólogo. Se o intuito é utilizar a CBO para descrever o cargo de Arquivista ou de Museólogo, poderia ser também

\footnotetext{
4 Famílias Ocupacionais que compõem o Subgrupo "Profíssionais da Comunicação e da Informação": Profissionais do jornalismo (código 2611); Profissionais da informação (código 2612); Arquivistas e museólogos (código 2613); Filólogos, tradutores, intérpretes e afins (código 2614); Profissionais da escrita (código 2615); Editores (código 2616); Locutores, comentaristas e repórteres de rádio e televisão (código 2617); Fotógrafos profissionais (código 2618).

5 Segundo pesquisas realizadas por Costa (2008, p. 98) nas fontes primárias do MTE/CBO, “o representante da arquivologia no comitê de definição das profissões não concordou com a inclusão dos arquivistas na família profissionais da informação" (COSTA, 2008, p. 98).

6 Por exemplo: O Edital de Concurso Público n ${ }^{\circ}$ 10, de 12 de maio de 2010, do Instituto Federal de Educação Ciência e Tecnologia Sertão Pernambucano; Edital n. 001/2013 - PROGEP, da Universidade Federal de Santa Maria.
} 
utilizada, apesar de suas limitações, os sinônimos dos títulos ocupacionais - Quadro 2 - e o relatório com a Tabela de Atividades do Museólogo ou do Arquivista da CBO 2002.

\section{Código: Título (Sinônimos)}

2613-05: Arquivista (Encarregado de serviço de arquivo médico e estatística; Gestor de documentos; Especialista em organização de arquivos; Especialista em documentação arquivística; Administrador de arquivos).

2613-10: Museólogo (Especialista em museografia de exposição; Auxiliar de museus; Especialista em documentação museológica; Especialista em educação em museus; Especialista em conservação de acervos; Conservador de museu).

Quadro 2 - Código e Título (Sinônimos) para os títulos ocupacionais de Arquivista e Museólogo na CBO 2002

Fonte: BRASIL, 2002b.

O relatório com a Tabela de Atividades para o Arquivista apresenta 128 atividades, as quais estão organizadas em 11 áreas. Para o Museólogo, são 123 atividades, organizadas em 12 áreas. Os dois profissionais possuem, em comum, 10 áreas, a saber: "Dar acesso à informação"; "Conservar acervos"; "Preparar ações educativas e/ou culturais"; "Planejar atividades técnicoadministrativas"; "Orientar a implantação de atividades técnicas"; "Participar da política de criação e implantação de museus e instituições arquivísticas"; "Realizar atividades técnicoadministrativas"; "Administrar atividades patrocinadas"; "Comunicar-se" e "Demonstrar competências pessoais" (BRASIL, 2002b). São áreas específicas do Museólogo: “Criar projetos de museus e exposições" e "Organizar acervos museológicos públicos e privados”. Para o Arquivista, é específica a área "Organizar documentação de arquivos institucionais e pessoais" (BRASIL, 2002b). O alto número de atividades e sub-atividades descritas na CBO, versão 2002, indica, segundo Liliana Segnini (apud SUGIMOTO, 2004), um acúmulo de tarefas, a intensificação do trabalho e a superestimação do profissional. 


\section{Uso da CBO nas estatísticas do mercado de trabalho}

A CBO é utilizada na Relação Anual de Informações Sociais, do Ministério de Trabalho e Emprego (RAIS/MTE), instituída pelo Decreto no . 76.900/75. A RAIS/MTE é um registro administrativo, com periodicidade anual, obrigatório para todos os estabelecimentos empregadores (PENA, 2007). Este instrumento governamental de coleta de dados do setor do trabalho formal contempla informações sobre os trabalhadores e sobre os estabelecimentos.

Uma vez que Arquivistas e Museólogos estão reunidos em uma mesma Família na CBO, as informações, a partir da RAIS/MTE, sobre o mercado de trabalho formal destes profissionais estão agregadas, de tal forma que não é possível desmembrar os dados das Ocupações de Arquivista e de Museólogo.

Para iniciar a caracterização atual da Família “Arquivistas e Museólogos”, pesquisaramse as informações da Família Ocupacional na base estatística da RAIS/MTE, que atendessem aos seguintes critérios: informações do ano de 2014, o qual é o último ano com dados disponibilizados para consulta pública nas bases estatísticas online da RAIS/MTE; existência de vínculo ativo do profissional no final do ano; e grau de escolaridade correspondente a Curso Superior completo, Mestrado e Doutorado7.

Os dados com o número de Arquivistas e Museólogos formalmente empregados nos estados brasileiros estão consolidados na Tabela 1, que será vista a seguir. A soma do quantitativo de profissionais em cada estado brasileiro totalizou 2.6528 pessoas formalmente empregadas como Arquivista e Museólogo no Brasil.

A análise dos dados da Tabela 1 permite observar que os estados que possuem o maior número de Arquivistas e Museólogos são Rio de Janeiro e São Paulo, na região Sudeste do país. O Distrito Federal, no Centro-oeste, é o terceiro colocado em maior quantitativo de profissionais. Em seguida, observa-se um número significativo de Arquivistas e Museólogos

\footnotetext{
7 No Brasil, ter o “curso superior” é uma exigência para ser considerado Museólogo (Lei n. 7.287/1984) ou Arquivista (Lei $n^{\circ}$. 6.546/78). O Museólogo, de acordo com a lei, também pode ser o pós-graduado em nível de Mestrado e de Doutorado em Museologia. Sobre a formação e a experiência da Família Ocupacional "Arquivistas e Museólogos", a CBO 2002 indica que: "As ocupações da Família requerem curso superior completo na área. Não é incomum, contudo a presença de profissionais com curso de especialização ou mesmo pós-graduação" (BRASIL, 2002b).

8 A pesquisa nas bases estatísticas online da RAIS/MTE restringiu-se ao nível de escolaridade correspondente a Curso Superior Completo, Mestrado e Doutorado. Se não houvesse esta restrição e fosse considerada qualquer escolaridade, a pesquisa retornaria um total de 7.274 profissionais, com $5^{\text {a }}$ Série incompleta, Ensino Fundamental completo, Ensino Médio, Graduado, Mestrado e Doutor.
}

InCID: R. Ci. Inf. e Doc., Ribeirão Preto, v. 8, n. 1, p. 46-67, mar./ago. 2017. 
no Rio Grande do Sul, em Minas Gerais e em Santa Catarina. No Nordeste, o estado da Bahia é o que possui maior número destes profissionais.

Tabela 1 - Quantitativo de Arquivistas e Museólogos formalmente empregados nos Estados

\begin{tabular}{l|r|l|r|l|r}
\hline \multicolumn{1}{c|}{ Estado } & $\mathbf{N}^{\mathbf{0}}$ & \multicolumn{1}{|c|}{ Estado } & $\mathbf{N}^{\mathbf{0}}$ & \multicolumn{1}{c|}{ Estado } & $\mathbf{N}^{\mathbf{0}}$ \\
\hline Rondônia & 4 & Ceará & 40 & Rio de Janeiro & 644 \\
Acre & 6 & Rio Grande do Norte & 16 & São Paulo & 521 \\
Amazonas & 25 & Paraíba & 61 & Paraná & 75 \\
Roraima & 2 & Pernambuco & 75 & Santa Catarina & 132 \\
Pará & 27 & Alagoas & 17 & Rio Grande do Sul & 215 \\
Amapá & 6 & Sergipe & 20 & Mato Grosso do Sul & 33 \\
Tocantins & 11 & Bahia & 108 & Mato Grosso & 21 \\
Maranhão & 91 & Minas Gerais & 150 & Goiás & 46 \\
Piauí & 9 & Espírito Santo & 63 & Distrito Federal & 234 \\
\hline
\end{tabular}

Fonte: Dados obtidos da base estatística RAIS/MTE (BRASIL, 2014).

Observa-se, ainda, na Tabela 1, que a região Norte é a que possui os estados com o menor número de Arquivistas e Museólogos. O estado de Roraima possui apenas 2 profissionais; Rondônia possui 4 profissionais; o Amapá e o Acre possuem 6 profissionais em cada estado. O Piauí, no Nordeste brasileiro, também apresenta um baixo número de profissionais, com apenas 9 Arquivistas e Museólogos.

Museólogo e Arquivista são profissões que, para serem exercidas, a legislação brasileira exige o diploma de nível superior. Em relação à população total do país, estes profissionais possuem um alto nível de escolaridade, o que explica sua maior presença nos estados com economias mais desenvolvidas, como, por exemplo, os estados das regiões Sul e Sudeste, e também no Distrito Federal, pelas características de sede administrativa do país e de centro político nacional (JANNUZZI; LOUREIRO, 2003).

Para conhecer as áreas de atuação dos Arquivistas e Museólogos formalmente empregados no Brasil, buscaram-se, na base estatística RAIS/MTE, informações sobre os setores econômicos dos empregadores, de acordo com a Classificação Nacional de Atividades Econômicas (CNAE)9, versão 2.0, no nível seção.

9 A Classificação de Atividades Econômicas (CNAE) é o instrumento de padronização das atividades econômicas, adotado pela Administração Pública, para identificar atividades econômicas em registros e cadastros de pessoa jurídica e pelo Sistema Estatístico Nacional na produção de estatísticas por tipo de atividade econômica (INSTITUTO BRASILEIRO DE GEOGRAFIA E ESTATÍSTICA, 2007). 
As informações revelaram que, do total de 2.652 Arquivistas e Museólogos empregados formalmente em 2014, 51,54\% dos profissionais estão empregados em apenas dois setores econômicos 10: “Administração Pública, Defesa e Seguridade Social” (780 profissionais, o que representa 29,41\% do total) e "Educação" (587 profissionais, o que representa 22,13\% do total). Outros setores que se destacam, com 100 ou mais profissionais, são: "Atividades Administrativas e Serviços Complementares" (196 profissionais); "Atividades Profissionais Científicas e Técnicas" (192 profissionais); "Informação e Comunicação" (170 profissionais); "Outras Atividades de Serviços" (155 profissionais) e "Saúde Humana e Serviços Sociais" (110 profissionais).

A fim de conhecer aprofundadamente onde os Arquivistas e Museólogos estão sendo mais empregados, buscou-se nas bases estatísticas da RAIS/MTE cruzar as informações do quantitativo de Arquivistas e Museólogos empregados na "Administração Pública, Defesa e Seguridade Social" e na "Educação" com as informações sobre a natureza jurídica do empregador. Este cruzamento de dados está consolidado na tabela a seguir:

Tabela 2 - Natureza Jurídica do Empregador e quantitativo de Arquivistas e Museólogos empregados nos setores “Administração Pública, Defesa e Seguridade Social" e "Educação"

\begin{tabular}{l|c|c}
\multicolumn{1}{c|}{\begin{tabular}{c}
\multicolumn{1}{c|}{ NATUREZA JURÍDICA DO } \\
EMPREGADOR
\end{tabular}} & $\begin{array}{c}\text { ADMINISTRAÇÃO } \\
\text { PÜBICA, DEFESA E } \\
\text { SEGURIDADE SOCIAL }\end{array}$ & EDUCAÇÃO \\
\hline $\begin{array}{l}\text { Poder Executivo (Federal, Estadual ou Distrito Federal e } \\
\text { Municipal) }\end{array}$ & 590 & 7 \\
Poder Legislativo (Estadual ou Distrito Federal e & 38 & 0 \\
Municipal) & 24 & 0 \\
Poder Judiciário (Federal) & 61 & 373 \\
Autarquia (Federal, Estadual ou Distrito Federal e & & 77 \\
Municipal) & 41 & 0 \\
Fundação (Federal e Municipal) & 2 & 1 \\
Órgão Público Autônomo Estadual ou Distrito Federal & 0 & 29 \\
SA Fechada & 0 & 42 \\
Sociedade (QT Ltda e Simples Ltda) & 24 & 9 \\
Outros / Fundação Privada & 0 & 49 \\
Serviço Social Autônomo & 0 & $\mathbf{5 8 7}$ \\
Outras Organizações - Associação Privada & $\mathbf{7 8 0}$ & \\
\hline
\end{tabular}

Fonte: Dados obtidos da base estatística RAIS/MTE (BRASIL, 2014).

10 A pesquisa apontou vinte setores econômicos, no nível seção da CNAE, que empregam formalmente a Família "Arquivistas e Museólogos". 
A Tabela 2 revela que o principal empregador dos Arquivistas e Museólogos é a administração pública, nos setores econômicos “Administração Pública, Defesa e Seguridade Social" e "Educação". O Poder Executivo é o que mais emprega Arquivistas e Museólogos, os quais atuam no setor econômico “Administração Pública, Defesa e Seguridade Social”. O setor econômico "Educação", por seu turno, emprega mais Arquivistas e Museólogos nas Autarquias. Conhecer a "natureza jurídica do empregador" dos setores econômicos que mais empregam Arquivistas e Museólogos permite afirmar que esta Família Ocupacional é composta, em sua maior parte, por servidores públicos.

\section{Conclusões parciais}

Em entrevista para o Jornal da Unicamp, Liliana Segnini (apud SUGIMOTO, 2004) afirma que: "conhecer, sistematizar, classificar o mercado de trabalho de um país significa elaborar parâmetros que informam relações econômicas, políticas e sociais”. E, mais adiante, explicita que as classificações de ocupações devem ser compreendidas como modos de "representar uma sociedade ou um país, considerando em sua elaboração parâmetros tecnológicos e sociais, tais como formação profissional, qualificação, representação sindical, relações e organização do trabalho" (SEGNINI apud SUGIMOTO, 2004). Por isso, apresentam configurações muito singulares. Já do ponto de vista da aplicação da classificação ocupacional às políticas públicas, vale citar Nozoe, Bianchi e Rondet (2003, p.245):

\footnotetext{
É sabido que a padronização da linguagem é elemento central quando se trata de informação da gestão pública. A elaboração de políticas públicas consistentes com a nossa realidade socioeconômica depende da qualidade da informação que recebem seus formuladores. Especificamente na gestão das políticas de emprego e de formação do trabalhador brasileiro, tal adequação fica condicionada à disponibilidade de informações padronizadas e atualizadas. Depende, portanto, da existência de uma rede de informações ocupacionais.

A publicação da CBO 2002 representou um passo importante na direção preconizada. Ela constitui um instrumento imprescindível de organização do levantamento de informações, análise e divulgação de dados pela administração do Estado, além de contribuir para normalizar os critérios de prestação de informações do setor privado ao poder público.
}

Algumas conclusões parciais podem ser inferidas a partir dos dados apresentados. Do ponto de vista das políticas públicas, fica evidente a grande dificuldade de se viabilizarem propostas sobre formação e emprego para Arquivistas e Museólogos, quando os dados quantitativos das duas profissões são agrupados em uma mesma Família Ocupacional. Neste caso, há indícios de que muitos Museólogos trabalhem em condições de informalidade nos museus brasileiros (DAMASCENO, 2015) e em Curadorias, por meio de ocupação informal; 
por outro lado, suspeita-se de que a maioria do trabalho arquivístico ocorra em regime de trabalho formal sendo, portanto, o Arquivista, e não o Museólogo, o principal representante da Família Ocupacional “Arquivistas e Museólogos” nos dados da RAIS/MTE. Só a desvinculação das duas profissões e dos dados estatísticos correspondentes permitiria uma completa observação da realidade. Do ponto de vista das políticas microinstitucionais, percebe-se que o uso equivocado da $\mathrm{CBO}$ na descrição ou atribuição de cargos nos editais de concurso público prejudica os profissionais em questão, uma vez que infringe o campo de jurisdição legal da profissão. São discussões muito importantes que serão objeto do avanço da pesquisa em curso.

\section{Referências}

BRASIL. Lei $\mathrm{n}^{\circ}$. 6.546, de 4 de julho de 1978. Dispõe sobre a regulamentação das profissões de Arquivista e de Técnico de Arquivo, e dá outras providências. Diário Oficial da União, Brasília, DF, 5 jul. 1978.

Lei $n^{\circ}$. 7.287, de 18 de novembro de 1984. Dispõe sobre a regulamentação da profissão de museólogo. Diário Oficial da União, Brasília, DF, 19 dez. 1984 e retificado em 21 dez. 1984.

Lei $n^{\circ} .8 .159$, de 8 de janeiro de 1991. Dispõe sobre a política nacional de arquivos públicos e privados e dá outras providências. Diário Oficial da União, Brasília, DF, 9 jan. 1991 e retificado em 28 jan. 1991.

. Portaria MTb nº 1.334, de 21 de dezembro de 1994. Aprova a classificação brasileira de ocupações - CBO, versão 94, para uso em todo território nacional. Diário Oficial da União, Brasília, DF, 23 dez. 1994.

. Ministério do Trabalho e Emprego. CBO - classificação brasileira de ocupações. Brasília: Ministério do Trabalho e Emprego, 2002a. Disponível em: <http://www.mtecbo.gov.br/cbosite/pages/home.jsf>. Acesso em: 22 nov. 2014.

Ministério do Trabalho e Emprego. Classificação brasileira de ocupações: busca por título: arquivistas e museólogos. Brasília: Ministério do Trabalho e Emprego, 2002b. Disponível em:

<http://www.mtecbo.gov.br/cbosite/pages/pesquisas/BuscaPorTituloResultado.jsf $>$. Acesso em: 27 jul. 2014.

Ministério do Trabalho e Emprego. Portaria n⿳0.397, de 09 de outubro de 2002. Aprova a classificação brasileira de ocupações - CBO/2002, para uso em todo o território nacional e autoriza sua publicação. Brasília: Ministério do Trabalho e Emprego, 2002c. Disponível em: 〈http://www.mtecbo.gov.br/cbosite/pages/legislacao.jsf>. Acesso em: 22 nov. 2014. 
Ministério do Trabalho e Emprego. Classificação brasileira de ocupações: CBO. Brasília: Ministério do Trabalho e Emprego; Secretaria de Políticas Públicas de Emprego, 2010a. Não paginado. Disponível em: <http://wp.ufpel.edu.br/observatoriosocial/files/2014/09/CBO-Livro-1.pdf > . Acesso em: 28 jan. 2016.

Ministério do Trabalho e Emprego. Edital de chamada pública de parcerias SPPE/MTE N'22/2010. Brasília: Ministério do Trabalho e Emprego, 2010b. Disponível em: <http://acesso.mte.gov.br/data/files/FF8080812BD96D6A012BE35B079A48CB/chp_SPPE_ 22_2010.pdf >. Acesso em: 23 out 2016.

. Ministério do Trabalho e Emprego. Bases estatísticas RAIS e CAGED. Brasília: Ministério do Trabalho e Emprego, 2014. Disponível em: <http://bi.mte.gov.br/bgcaged/login.php>. Acesso em: 28 jul. 2014.

. Ministério do Trabalho e Emprego. Base CBO. Grupo de base bibliotecários, arquivologistas e museólogos. Brasília: Ministério do Trabalho e Emprego, [199-?].

Disponível em:

<http://consulta.mte.gov.br/empregador/cbo/procuracbo/conteudo/tabela3.asp?gg=1\&sg=9\&g $\underline{b=1}>$. Acesso em: 13 ago. 2015.

COSTA, L. C. Entre a formação e o trabalho: o arquivista diante das novas demandas sociais e organizacionais em matéria de informação. 2008.168f. Dissertação (Mestrado em Ciência da Informação) - Faculdade de Economia, Administração, Contabilidade e Ciência da Informação e Documentação, Universidade de Brasília, Brasília, 2008.

DAMASCENO, W. M. F. A situação dos museólogos brasileiros: uma análise sobre trabalho e precarização. In: VI SEMINÁRIO NACIONAL DE SOCIOLOGIA E POLÍTICA DA UFPR, 6, 2015, Curitiba. Anais... Grupo de Trabalho 04 - trabalho e sindicalismo, 2015. p. 01-17. Disponível em: <http://www.edemocracia.com.br/sociologia/anais_2015/pdf/AN4B.pdf>. Acesso em: 12 set. 2015.

INSTITUTO BRASILEIRO DE GEOGRAFIA E ESTATÍSTICA. Classificação Nacional de Atividades Econômicas. Versão 2.0. Rio de Janeiro: IBGE, 2007.

Comissão Nacional de Classificação. Classificação Brasileira de Ocupações. Brasília: IBGE; Comissão Nacional de Classificação, 2015. Disponível em: <http://concla.ibge.gov.br/classificacoes/por-tema/ocupacao/classificacao-brasileira-deocupacoes>. Acesso em: 31 mai 2015.

JANNUZZI, P. M.; LOUREIRO, M. F. Equipamentos culturais, bibliotecas e profissionais da informação no Brasil: indicadores estaduais por volta de 2000. Transinformação, Campinas, v.15, n. 3 (Edição Especial), p.23-44, set/dez, 2003.

MARQUES, A. A. C. A arquivologia no Brasil: algumas considerações históricas e sua configuração atual. In: RODRIGUES, G. M.; COSTA, M. G. (Org.). Arquivologia: configuração da pesquisa no Brasil: epistemologia, formação, preservação, uso e acesso. Brasília: Editora Universidade de Brasília, 2012. p.21-36. 
MARQUES, A. A. C.; RODRIGUES, G. M. A configuração da pesquisa em arquivologia no Brasil: delineamentos dos seus espaços e temáticas. In: MARQUES, A. A. C; RONCAGLIO, C.; RODRIGUES, G. M. (Org.). A formação e a pesquisa nas universidades públicas brasileiras: I reunião brasileira de ensino e pesquisa em arquivologia. Brasília: Thesaurus, 2011. p.77-107.

NOZOE, N. H.; BIANCHI, A. M.; RONDET, A. C. A. A nova classificação brasileira de ocupações: anotações de uma pesquisa empírica. São Paulo em Perspectiva, São Paulo, v.17, n.3-4, p.234-246, dez. 2003. Disponível em:

$<$ http://www.scielo.br/scielo.php?script=sci_arttext\&pid=S0102$\underline{88392003000300023 \& \operatorname{lng}=\mathrm{en} \& \mathrm{nrm}=\mathrm{iso}>}>$. Acesso em 07 nov. 2016.

NUNES, G. A.; OLIVEIRA, A. C. A. R.; COSTA, C. A. S. A arquitetura de museus nos cursos de graduação em museologia no Brasil. In: SEMINÁRIO INTERNACIONAL MUSEOGRAFIA E ARQUITETURA DE MUSEUS: identidades e comunicação, 2, 2010, Rio de Janeiro. Anais... Rio de Janeiro: FAU/PROARQ, 2010.

ORGANIZAÇÃO INTERNACIONAL DO TRABALHO. Resolución sobre la actualización de la clasificación internacional uniforme de ocupaciones. Genebra (Suíça): Organização Internacional do Trabalho, [200-?]. Disponível em: $<$ http://www.ilo.org/public/spanish/bureau/stat/isco/docs/resol08.pdf $>$. Acesso em 15 ago. 2015 .

PENA, A. S. A evolução do mercado de trabalho formal do profissional da Informação no Brasil: um estudo a partir da RAIS/MTE, 1992-2005. 2007.165f. Dissertação (Mestrado em Ciência da Informação) - Escola de Ciência da Informação, Universidade Federal de Minas Gerais, Belo Horizonte, 2007.

RODRIGUES, G. M. Apresentação. In: MARQUES, A. A. C; RONCAGLIO, C.; RODRIGUES, G. M. (Org.). A formação e a pesquisa nas universidades públicas brasileiras: I Reunião Brasileira de Ensino e Pesquisa em Arquivologia. Brasília: Thesaurus, 2011. p.11-16.

SÁ, I. C. As matrizes francesas e origens comuns no Brasil dos cursos de formação em Arquivologia, Biblioteconomia e Museologia. Acervo, v. 26, p. 31-58, jul./dez. 2013.

SANTOS, P. R. E. A pesquisa em Arquivologia no Brasil e os centros não universitários: apontamentos para um debate. In: MARIZ, A. C. A.; JARDIM, J. M.; SILVA, S. C. A. (Org.). Novas dimensões da pesquisa e do ensino da arquivologia no Brasil. Rio de Janeiro: Móbile; Associação dos Arquivistas do Estado do Rio de Janeiro, 2012.

SOUZA, K. I. M. Arquivista, visibilidade profissional: formação, associativismo e mercado de trabalho. Brasília: Starprint, 2011.

SUGIMOTO, L. O ofício de cada um. Jornal da Unicamp, n. 256, p. 3, jun. 2004.

Disponível em:

<http://www.unicamp.br/unicamp/unicamp_hoje/ju/junho2004/ju256pag03.html > . Acesso em: 10 jul. 2015. 
TANUS, G. F. S. C. Cenário acadêmico institucional dos cursos de arquivologia, biblioteconomia e museologia do Brasil. 2013. 242f. Dissertação (Mestrado em Ciência da Informação) - Escola de Ciência da Informação, Universidade Federal de Minas Gerais, Belo Horizonte, 2013.

UNIVERSIDADE DE BRASÍLIA. Faculdade de Ciência da Informação. Curso de Arquivologia. I reunião brasileira de ensino e pesquisa em arquivologia. Brasília, 07 a 09 de junho de 2010. Deliberações, recomendações e monção. Brasília: UnB, 2010. Disponível em:

〈http://www.aaerj.org.br/wp-content/uploads/2010/11/I-REPA-RECOMENDAES.pdf.pdf $>$. Acesso em 18 jun. 2015. 